Curr Opin HIV AIDS. 2010 September ; 5(5): 386-390. doi:10.1097/COH.0b013e32833cfe4c.

\title{
Novel Adenovirus Vector-Based Vaccines for HIV-1
}

\author{
Dan H. Barouch \\ Division of Vaccine Research, Beth Israel Deaconess Medical Center, Boston, MA 02215; Ragon, \\ Institute of MGH, MIT, and Harvard, Boston, MA 02114
}

\begin{abstract}
Purpose of Review-Recombinant adenovirus (rAd) vectors have emerged as promising vaccine platform technologies due to their capacity to elicit potent humoral and cellular immune responses to encoded antigens. These vectors are being explored as potential vaccine candidates for a variety of pathogens. This review summarizes current efforts to develop rAd vector-based vaccines for HIV-1.
\end{abstract}

Recent Findings-In the phase 2b Step study, rAd5 vectors expressing clade B HIV-1 Gag, Pol, and Nef antigens failed to afford protection and may have resulted in increased HIV-1 acquisition in certain subgroups. Recent studies have explored the potential reasons for this failure and the utility of novel rAd vectors derived from non-Ad5 serotypes.

Summary-Current areas of active investigation include the development of alternative serotype rAd vectors, the incorporation of rAd vectors into heterologous vector prime-boost regimens, and the use of rAd vectors to express novel HIV-1 antigens. These HIV-1 vaccine candidates will be evaluated in clinical trials over the next several years.

\section{Keywords}

HIV-1; Adenovirus; Vaccine

\section{Introduction}

Three HIV-1 vaccine concepts have completed clinical efficacy trials to date. The AIDSVAX studies (VAX003/004) were completed in 2003 and showed that monomeric Env gp120 proteins failed to afford protection against HIV-1 acquisition in high-risk subjects in the U.S. and Thailand (1-2). The Step study (HVTN 502/Merck 023) evaluated rAd5 vectors expressing clade B Gag, Pol, and Nef in high-risk individuals in North America, South America, the Caribbean, and Australia. Vaccinations in this study were unexpectedly terminated in 2007 for futility and for a trend towards increased HIV-1 acquisition in vaccinees as compared with placebo recipients (3). The Thai trial (RV144) evaluated an ALVAC prime, Env gp120 protein boost regimen and demonstrated in 2009 a $31 \%$ protective effect against acquisition of HIV-1 infection in low-risk, heterosexual subjects in Thailand (4).

The Thai trial provided the first signal of HIV-1 vaccine efficacy in humans. However, the observed protection was modest and transient in nature, and more potent vaccine candidates will presumably be required. A diversity of approaches should therefore continue to be pursued in the HIV-1 vaccine field. Platform technologies that are being explored include the use of

Correspondence: Dan H. Barouch, E/CLS - 1047, 330 Brookline Avenue, Boston, MA 02215, Phone: 617-735-4485, Fax: 617-735-4527, dbarouch@bidmc.harvard.edu.

The author declares no financial conflicts of interest. 
adenovirus vectors, poxvirus vectors, DNA vaccines, protein subunits, and other approaches. This review summarizes current efforts to develop rAd vector-based vaccines for HIV-1.

\section{Implications of the Step Study}

Recombinant Ad5 vectors were selected for development by both Merck and the NIH Vaccine Research Center (VRC) based on their immunologic potency and manufacturing feasibility. This decision was based in part on comparative preclinical immunogenicity studies that showed that rAd5 vectors elicited higher magnitude cellular and humoral immune responses than poxvirus vectors and DNA vaccines (5-6). The Merck HIV-1 vaccine candidate was formulated as a trivalent mixture of rAd5 vectors expressing clade B Gag, Pol, and Nef. Merck together with the NIH-sponsored HIV Vaccine Trials Network (HVTN) advanced this vaccine candidate into a phase 2 b efficacy trial called the Step study in North America, South America, the Caribbean, and Australia (3,7). A second phase 2 b efficacy trial called Phambili was initiated in South Africa utilizing this same vaccine.

Vaccinations in the Step study were unexpectedly terminated in 2007 at the first data and safety monitoring board review for futility. A trend towards increased HIV-1 acquisition was also observed in vaccinees as compared with placebo recipients, particularly in subjects who had baseline Ad5 neutralizing antibodies (NAbs) and who were uncircumcised (3). Based on these findings, vaccinations in the Phambili study were also terminated, and the phase $2 \mathrm{~b}$ evaluation of the DNA prime, rAd5 boost vaccine candidate developed by the VRC was delayed and modified.

The results of the Step study have had a profound impact on the field but have also proven difficult to interpret. In particular, the trend towards increased acquisition of HIV-1 infection in baseline Ad5 seropositive vaccinees was concerning but was not statistically significant $(3,8)$. Other clinical variables such as geography and circumcision status may also have impacted HIV-1 acquisition risk in this study. Nevertheless, a hypothesis emerged shortly after the Step results were announced that baseline Ad5 NAbs may have been markers for Ad5specific T lymphocyte responses, and that Ad5-specific CD4+ T lymphocytes could have expanded following rAd5 vaccination and served as increased targets for infection at mucosal sites. Several groups have now explored the immunologic basis of this hypothesis.

Four independent laboratories have assessed Ad5-specific T lymphocyte responses in humans with and without baseline Ad5 NAbs following rAd5 vaccination (9-12). In particular, Ad5 $\mathrm{NAb}$ titers were shown not to correlate with Ad5-specific T lymphocyte responses, presumably as a result of extensive cross-reactive $\mathrm{T}$ lymphocyte responses across multiple Ad serotypes. Moreover, following rAd5 vaccination, Ad5-specific CD4+ T lymphocyte responses were comparable or lower in baseline Ad5 seropositive subjects as compared with baseline Ad5 seronegative subjects, likely reflecting partial neutralization of the rAd5 vaccine vector in subjects with baseline Ad5 NAbs. Thus, no greater anamnestic vector-specific CD4+ T lymphocyte responses were observed following rAd5 vaccination in subjects with baseline Ad5 NAbs. These findings do not support the hypothesis that exuberant Ad5-specific CD4+ T lymphocyte responses led to the potential increased HIV-1 acquisition in baseline Ad5 seropositive individuals in the Step study.

A caveat of all these studies is that analyses performed using peripheral blood lymphocytes do not exclude the possibility that robust vector-specific CD4+ T lymphocytes may have trafficked rapidly to mucosal sites. Consistent with this possibility, an in vitro study reported activation of Ad5-specific CD4+ T lymphocytes and upregulation of mucosal homing integrin expression following short-term in vitro cultures with large amounts of Ad5 virus (13). The interpretation of this study, however, is limited by the lack of evaluation of subjects following rAd5 
vaccination and, similar to the previous studies, the absence of direct assessments of cellular inflammation and vector-specific CD4+ T lymphocyte responses at mucosal surfaces. Answering this question definitively would require an analysis of mucosal biopsies from humans with and without baseline Ad5 NAbs following rAd5 vaccination. Unfortunately, these data are unlikely to be readily obtained.

We have recently explored this hypothesis in a rhesus monkey model in which baseline Ad5 immunity was induced by respiratory infection with replication-competent Ad5 virus (14). In this model, we showed that Ad5-specific CD4+ T lymphocyte responses at mucosal sites following $\mathrm{rAd} 5-\mathrm{Gag} / \mathrm{Pol} / \mathrm{Nef}$ vaccination were comparable in rhesus monkeys with and without baseline Ad5 NAbs. Moreover, total cellular inflammatory infiltrates as well as CD3, CD4, HLA-DR, Ki67, and Langerin-positive cellular subpopulations in colorectal and foreskin mucosa were similar in both groups. Thus, no greater trafficking of Ad5-specific CD4+ T lymphocytes to mucosal target sites was observed following rAd5 vaccination of baseline Ad5 seropositive as compared with baseline Ad5 seronegative rhesus monkeys. We did observe transient activation of Ad5-specific CD4+ T lymphocytes at week 1 following vaccination, consistent with the in vitro findings (13) and prior nonhuman primate studies (15), but this cellular activation rapidly returned to baseline levels by week 2 following vaccination in both the periphery and the mucosa. These data, together with the immunologic data obtained from human peripheral blood lymphocytes following rAd5 vaccination (9-12), suggest that recruitment of vector-specific target cells to mucosal sites does not likely account for the potential increased HIV-1 acquisition for $>52$ weeks in Ad5 seropositive, uncircumcised vaccinees in the Step study.

An alternative hypothesis that has been proposed is that rAd5 vaccination of subjects with baseline Ad5 NAbs may have resulted in antigen-antibody immune complexes that could have triggered more rapid or more efficient stimulation of dendritic cells (16). The possible connection of these parameters with susceptibility to HIV-1 infection is currently being explored. Still another possibility is that baseline Ad5 NAbs may not in fact have been causally related to increased HIV-1 acquisition in rAd5 vaccinees in the Step study. Consistent with this possibility is the lack of a statistically significant association between these two variables at any point in time (8). Lack of circumcision appears to be the clinical parameter most strongly associated with increased HIV-1 acquisition in post-hoc multivariate analyses of the Step study (8), although no convincing mechanism has to date been proposed to explain this trend.

\section{Next Generation Adenovirus Vector Strategies}

Regardless of the debate surrounding the potential enhancement of HIV-1 acquisition in the Step study, it is clear that the rAd5 vaccine failed to afford protection in this population. It is unclear whether this was due to insufficient magnitude, breadth, or functionality of cellular immune responses, absence of Env-specific antibody responses, or inadequate immunologic coverage of infecting viruses. Interestingly, the vaccine did appear to increase immune selection pressure on certain epitopes in gag, pol, and nef following HIV-1 infection (17). These data suggest that the rAd5 vaccine did in fact have an immunologic impact on infecting viruses, although it also highlights the capacity of HIV-1 to evade vaccine-elicitied CD8+ T lymphocyte responses, consistent with preclinical findings (18-19).

Ongoing efforts in the development of next generation rAd vector-based vaccines for HIV-1 include the development of alternative serotype rAd vectors, the incorporation of rAd vectors into heterologous vector prime-boost regimens, and the use of rAd vectors to express novel HIV-1 antigens to improve immunologic coverage of circulating viruses. Novel rAd vectors that are being explored include rare human serotype vectors such as rAd26 and rAd35 (2021 ), hexon-chimeric vectors such as rAd5HVR48 (22), and vectors derived from chimpanzees 
(23-24) as well as other species. These vectors may have important advantages over rAd5 vectors as a result of their lower seroprevalence and NAb titers as well as their capacity to evade Ad5-specific immunity in preclinical studies $(21,24-25)$. Several of these vectors, including rAd26, rAd35, and rAd5HVR48, are currently being evaluated in phase 1 clinical trials. The potential impact of cross-reactive Ad-specific T lymphocyte responses and low baseline NAb titers on vector immunogenicity is currently being investigated.

The alternative serotype rAd vectors are also biologically substantially different than rAd5 vectors. Certain serotypes from Ad subgroups B and D utilize CD46 rather than CAR as their cellular receptors (20-21), exhibit different in vivo tropism with reduced liver transduction (26), interact differentially with dendritic cell subsets (27), induce different innate immune profiles and adaptive immune phenotypes (28), and afford improved protective efficacy against SIV in nonhuman primates (29). The growing portfolio of available rAd vectors therefore offers substantial biologic diversity in addition to different capsid neutralization determinants.

The incorporation of rAd vectors into heterologous prime-boost regimens is also an area of active investigation. The most advanced concept involves a DNA prime, rAd5 boost regimen (30-31). DNA priming prior to rAd5 boosting has been shown to enhance antigen-specific immune responses, but several groups have reported that this does not improve protective efficacy against SIV challenges in rhesus monkeys (32-34). A phase $2 b$ clinical trial (HVTN 505 ) is currently in progress to evaluate the protective efficacy of the VRC DNA prime, rAd5 boost vaccine candidate expressing clade B Gag, Pol, Nef and clades A/B/C Env in high-risk subjects. Other heterologous prime-boost regimens include the use of two serologically distinct rAd vectors $(29,35-37)$, some of which have been shown to be more efficacious than rAd5 alone regimens against SIV challenges in rhesus monkeys (29); rAd prime, recombinant poxvirus boost regimens (38); and rAd prime, Env protein boost regimens. These and other regimens are planned for evaluation in clinical trials over the next several years.

The use of rAd vectors as a platform for exploring novel HIV-1 antigens is another area of current investigation. One example is the development of synthetic HIV-1 antigens that optimize cellular immune coverage of global HIV-1 diversity using a bioinformatics approach (39). These "mosaic" antigens have been shown to expand cellular immune breadth and depth as compared with consensus or natural sequence antigens in the context of DNA prime, rAd5 boost regimens in mice (40); in the context of rAd26 prime, rAd5HVR48 boost regimens in nonhuman primates (41); and in the context of DNA prime, recombinant vaccinia virus boost regimens in nonhuman primates (42). Recombinant Ad vectors may be particularly well suited for expression of mosaic HIV-1 antigens given their capacity to induce robust CD8+ T lymphocyte responses.

\section{Conclusions}

Substantial recent progress has been made in the development of rAd vector-based vaccines for HIV-1. Multiple laboratories have explored various hypotheses raised by the Step study, and alternative serotype rAd vectors and heterologous vector prime-boost regimens have been developed. Novel rAd vector regimens expressing improved HIV-1 antigens are planned for clinical evaluation in the near future. The possibility of rAd vector priming for subsequent Env protein boosting also warrants further evaluation. It will be important to define the biologic differences between various rAd serotypes in humans as well as to incorporate detailed safety monitoring into clinical trials of novel rAd vectors.

As a result of the Thai trial, additional clinical studies of recombinant poxvirus prime, Env protein boost regimens are clearly warranted. However, maintaining a diversity of HIV-1 vaccine approaches is also critical, since the correlates of immune protection remain unknown 
and since it is not clear which vector regimens or vaccine antigens will ultimately prove successful. It is sobering to acknowledge the fact that only three vaccine concepts have completed clinical efficacy testing to date, despite over 25 years of intensive worldwide research in the HIV-1 vaccine field. Moreover, the results of all efficacy trials have been unexpected and have not been predicted based on preclinical and early phase clinical trials. One can argue that testing only three vaccine concepts is insufficient for one of the greatest global health problems and that advancing a limited number of additional vaccine candidates into clinical efficacy trials is therefore warranted over the next several years.

\section{Acknowledgments}

The author acknowledges support from the National Institutes of Health (AI066305, AI066924, AI078526, AI084794), the Bill and Melinda Gates Foundation, the Henry M. Jackson Foundation, and the Ragon Institute of MGH, MIT, and Harvard.

\section{References}

1. Flynn NM, Forthal DN, Harro CD, Judson FN, Mayer KH, Para MF. Placebo-controlled phase 3 trial of a recombinant glycoprotein 120 vaccine to prevent HIV-1 infection. The Journal of infectious diseases 2005;191:654-65. [PubMed: 15688278]

2. Pitisuttithum P, Gilbert P, Gurwith M, Heyward W, Martin M, van Griensven F, Hu D, Tappero JW, Choopanya K. Randomized, double-blind, placebo-controlled efficacy trial of a bivalent recombinant glycoprotein 120 HIV-1 vaccine among injection drug users in Bangkok, Thailand. The Journal of infectious diseases 2006;194:1661-71. [PubMed: 17109337]

3. Buchbinder SP, Mehrotra DV, Duerr A, Fitzgerald DW, Mogg R, Li D, Gilbert PB, Lama JR, Marmor M, Del Rio C, McElrath MJ, Casimiro DR, Gottesdiener KM, Chodakewitz JA, Corey L, Robertson MN. Efficacy assessment of a cell-mediated immunity HIV-1 vaccine (the Step Study): a double-blind, randomised, placebo-controlled, test-of-concept trial. Lancet 2008;372:1881-93. [PubMed: 19012954]

4**. Rerks-Ngarm S, Pitisuttithum P, Nitayaphan S, Kaewkungwal J, Chiu J, Paris R, Premsri N, Namwat C, de Souza M, Adams E, Benenson M, Gurunathan S, Tartaglia J, McNeil JG, Francis DP, Stablein D, Birx DL, Chunsuttiwat S, Khamboonruang C, Thongcharoen P, Robb ML, Michael NL, Kunasol P, Kim JH. Vaccination with ALVAC and AIDSVAX to prevent HIV-1 infection in Thailand. N Engl J Med 2009;361:2209-20. This study reports the first evidence of protective efficacy by an HIV-1 vaccine in humans. [PubMed: 19843557]

5. Shiver JW, Fu TM, Chen L, Casimiro DR, Davies ME, Evans RK, Zhang ZQ, Simon AJ, Trigona WL, Dubey SA, Huang L, Harris VA, Long RS, Liang X, Handt L, Schleif WA, Zhu L, Freed DC, Persaud NV, Guan L, Punt KS, Tang A, Chen M, Wilson KA, Collins KB, Heidecker GJ, Fernandez VR, Perry HC, Joyce JG, Grimm KM, Cook JC, Keller PM, Kresock DS, Mach H, Troutman RD, Isopi LA, Williams DM, Xu Z, Bohannon KE, Volkin DB, Montefiori DC, Miura A, Krivulka GR, Lifton MA, Kuroda MJ, Schmitz JE, Letvin NL, Caulfield MJ, Bett AJ, Youil R, Kaslow DC, Emini EA. Replication-incompetent adenoviral vaccine vector elicits effective anti-immunodeficiency-virus immunity. Nature 2002;415:331-5. [PubMed: 11797011]

6. Shiver JW, Emini EA. Recent advances in the development of HIV-1 vaccines using replicationincompetent adenovirus vectors. Annu Rev Med 2004;55:355-72. [PubMed: 14746526]

7. McElrath MJ, De Rosa SC, Moodie Z, Dubey S, Kierstead L, Janes H, Defawe OD, Carter DK, Hural J, Akondy R, Buchbinder SP, Robertson MN, Mehrotra DV, Self SG, Corey L, Shiver JW, Casimiro DR. HIV-1 vaccine-induced immunity in the test-of-concept Step Study: a case-cohort analysis. Lancet 2008;372:1894-905. [PubMed: 19012957]

8. Buchbinder, S. Keystone Symposium on HIV Vaccines. Keystone, CO: 2009. Clinical endpoints in the Step study.

9*. O’Brien KL, Liu J, King SL, Sun YH, Schmitz JE, Lifton MA, Hutnick NA, Betts MR, Dubey SA, Goudsmit J, Shiver JW, Robertson MN, Casimiro DR, Barouch DH. Adenovirus-specific immunity after immunization with an Ad5 HIV-1 vaccine candidate in humans. Nat Med 2009;15:873-5. This study shows that Ad5-specific CD4+ T lymphocyte responses are no higher in baseline Ad5 
seropositive as compared with baseline Ad5 seronegative humans following vaccination with the Merck rAd5-Gag vaccine. [PubMed: 19620961]

10*. Hutnick NA, Carnathan DG, Dubey S, Cox K, Ratcliffe S, Robertson MN, Casimiro DR, Ertl HC, Betts MR. The effects of adenovirus based HIV-1 vaccines on CD4+ T cells in humans. Nat Med 2009;15:876-8. This study shows that Ad5-specific CD4+ T lymphocyte responses are no higher in baseline Ad5 seropositive as compared with baseline Ad5 seronegative humans following vaccination with the Merck rAd5-Gag vaccine. [PubMed: 19620962]

11. Koup RA, Lamoreaux L, Zarkowsky D, Bailer RT, King CR, Gall JG, Brough DE, Graham BS, Roederer M. Replication-defective adenovirus vectors with multiple deletions do not induce measurable vector-specific T cells in human trials. J Virol 2009;83:6318-22. [PubMed: 19339347]

12. D'Souza MP, Frahm N. Adenovirus 5 serotype vector-specific immunity and HIV-1 infection: a tale of T cells and antibodies. Aids 2010;24:803-9. [PubMed: 20168203]

13. Benlahrech A, Harris J, Meiser A, Papagatsias T, Hornig J, Hayes P, Lieber A, Athanasopoulos T, Bachy V, Csomor E, Daniels R, Fisher K, Gotch F, Seymour L, Logan K, Barbagallo R, Klavinskis L, Dickson G, Patterson S. Adenovirus vector vaccination induces expansion of memory CD4 T cells with a mucosal homing phenotype that are readily susceptible to HIV-1. Proc Natl Acad Sci U S A 2009;106:19940-5. [PubMed: 19918060]

14. Barouch, DH. Heterologous rare serotype adenovirus vectors for HIV-1. Keystone Symposium on HIV Vaccines; Banff, Canada. 2010.

15. Sun Y, Bailer RT, Rao SS, Mascola JR, Nabel GJ, Koup RA, Letvin NL. Systemic and mucosal Tlymphocyte activation induced by recombinant adenovirus vaccines in rhesus monkeys. J Virol 2009;83:10596-604. [PubMed: 19656883]

16. Perreau M, Pantaleo G, Kremer EJ. Activation of a dendritic cell-T cell axis by Ad5 immune complexes creates an improved environment for replication of HIV in T cells. The Journal of experimental medicine 2008;205:2717-25. [PubMed: 18981239]

17. Mullins, J. AIDS Vaccine 2009. Paris, France: 2009. Evidence of vaccine-induced changes in breakthrough HIV-1 strains from the Step trial.

18. Barouch DH, Kunstman J, Glowczwskie J, Kunstman KJ, Egan MA, Peyerl FW, Santra S, Kuroda MJ, Schmitz JE, Beaudry K, Krivulka GR, Lifton MA, Gorgone DA, Wolinsky SM, Letvin NL. Viral escape from dominant simian immunodeficiency virus epitope-specific cytotoxic T lymphocytes in DNA-vaccinated rhesus monkeys. J Virol 2003;77:7367-75. [PubMed: 12805435]

19. Barouch DH, Kunstman J, Kuroda MJ, Schmitz JE, Santra S, Peyerl FW, Krivulka GR, Beaudry K, Lifton MA, Gorgone DA, Montefiori DC, Lewis MG, Wolinsky SM, Letvin NL. Eventual AIDS vaccine failure in a rhesus monkey by viral escape from cytotoxic T lymphocytes. Nature 2002;415:335-9. [PubMed: 11797012]

20. Vogels R, Zuijdgeest D, van Rijnsoever R, Hartkoorn E, Damen I, de Bethune MP, Kostense S, Penders G, Helmus N, Koudstaal W, Cecchini M, Wetterwald A, Sprangers M, Lemckert A, Ophorst O, Koel B, van Meerendonk M, Quax P, Panitti L, Grimbergen J, Bout A, Goudsmit J, Havenga M. Replication-deficient human adenovirus type 35 vectors for gene transfer and vaccination: efficient human cell infection and bypass of preexisting adenovirus immunity. J Virol 2003;77:8263-71. [PubMed: 12857895]

21. Abbink P, Lemckert AA, Ewald BA, Lynch DM, Denholtz M, Smits S, Holterman L, Damen I, Vogels R, Thorner AR, O’Brien KL, Carville A, Mansfield KG, Goudsmit J, Havenga MJ, Barouch DH. Comparative seroprevalence and immunogenicity of six rare serotype recombinant adenovirus vaccine vectors from subgroups B and D. J Virol 2007;81:4654-63. [PubMed: 17329340]

22. Roberts DM, Nanda A, Havenga MJ, Abbink P, Lynch DM, Ewald BA, Liu J, Thorner AR, Swanson PE, Gorgone DA, Lifton MA, Lemckert AA, Holterman L, Chen B, Dilraj A, Carville A, Mansfield KG, Goudsmit J, Barouch DH. Hexon-chimaeric adenovirus serotype 5 vectors circumvent preexisting anti-vector immunity. Nature 2006;441:239-43. [PubMed: 16625206]

23. Farina SF, Gao GP, Xiang ZQ, Rux JJ, Burnett RM, Alvira MR, Marsh J, Ertl HC, Wilson JM. Replication-defective vector based on a chimpanzee adenovirus. J Virol 2001;75:11603-13. [PubMed: 11689642]

24. Fitzgerald JC, Gao GP, Reyes-Sandoval A, Pavlakis GN, Xiang ZQ, Wlazlo AP, Giles-Davis W, Wilson JM, Ertl HC. A simian replication-defective adenoviral recombinant vaccine to HIV-1 gag. J Immunol 2003;170:1416-22. [PubMed: 12538702] 
25. Barouch DH, Pau MG, Custers JH, Koudstaal W, Kostense S, Havenga MJ, Truitt DM, Sumida SM, Kishko MG, Arthur JC, Korioth-Schmitz B, Newberg MH, Gorgone DA, Lifton MA, Panicali DL, Nabel GJ, Letvin NL, Goudsmit J. Immunogenicity of recombinant adenovirus serotype 35 vaccine in the presence of pre-existing anti-Ad5 immunity. J Immunol 2004;172:6290-7. [PubMed: 15128818]

26. Waddington SN, McVey JH, Bhella D, Parker AL, Barker K, Atoda H, Pink R, Buckley SM, Greig JA, Denby L, Custers J, Morita T, Francischetti IM, Monteiro RQ, Barouch DH, van Rooijen N, Napoli C, Havenga MJ, Nicklin SA, Baker AH. Adenovirus serotype 5 hexon mediates liver gene transfer. Cell 2008;132:397-409. [PubMed: 18267072]

27. Lore K, Adams WC, Havenga MJ, Precopio ML, Holterman L, Goudsmit J, Koup RA. Myeloid and plasmacytoid dendritic cells are susceptible to recombinant adenovirus vectors and stimulate polyfunctional memory T cell responses. J Immunol 2007;179:1721-9. [PubMed: 17641038]

28. Liu J, Ewald BA, Lynch DM, Denholtz M, Abbink P, Lemckert AA, Carville A, Mansfield KG, Havenga MJ, Goudsmit J, Barouch DH. Magnitude and phenotype of cellular immune responses elicited by recombinant adenovirus vectors and heterologous prime-boost regimens in rhesus monkeys. J Virol 2008;82:4844-52. [PubMed: 18337575]

29. Liu J, O’Brien KL, Lynch DM, Simmons NL, La Porte A, Riggs AM, Abbink P, Coffey RT, Grandpre LE, Seaman MS, Landucci G, Forthal DN, Montefiori DC, Carville A, Mansfield KG, Havenga MJ, Pau MG, Goudsmit J, Barouch DH. Immune control of an SIV challenge by a T-cell-based vaccine in rhesus monkeys. Nature 2009;457:87-91. [PubMed: 18997770]

30. Koup RA, Roederer M, Lamoreaux L, Fischer J, Novik L, Nason MC, Larkin BD, Enama ME, Ledgerwood JE, Bailer RT, Mascola JR, Nabel GJ, Graham BS. Priming immunization with DNA augments immunogenicity of recombinant adenoviral vectors for both HIV-1 specific antibody and T-cell responses. PLoS ONE 2010;5:e9015. [PubMed: 20126394]

31. Santra S, Seaman MS, Xu L, Barouch DH, Lord CI, Lifton MA, Gorgone DA, Beaudry KR, Svehla K, Welcher B, Chakrabarti BK, Huang Y, Yang ZY, Mascola JR, Nabel GJ, Letvin NL. Replicationdefective adenovirus serotype 5 vectors elicit durable cellular and humoral immune responses in nonhuman primates. J Virol 2005;79:6516-22. [PubMed: 15858035]

32. Letvin NL, Mascola JR, Sun Y, Gorgone DA, Buzby AP, Xu L, Yang ZY, Chakrabarti B, Rao SS, Schmitz JE, Montefiori DC, Barker BR, Bookstein FL, Nabel GJ. Preserved CD4+ central memory T cells and survival in vaccinated SIV-challenged monkeys. Science 2006;312:1530-3. [PubMed: 16763152]

33. Casimiro DR, Wang F, Schleif WA, Liang X, Zhang ZQ, Tobery TW, Davies ME, McDermott AB, O'Connor DH, Fridman A, Bagchi A, Tussey LG, Bett AJ, Finnefrock AC, Fu TM, Tang A, Wilson KA, Chen M, Perry HC, Heidecker GJ, Freed DC, Carella A, Punt KS, Sykes KJ, Huang L, Ausensi VI, Bachinsky M, Sadasivan-Nair U, Watkins DI, Emini EA, Shiver JW. Attenuation of simian immunodeficiency virus SIVmac239 infection by prophylactic immunization with dna and recombinant adenoviral vaccine vectors expressing Gag. J Virol 2005;79:15547-55. [PubMed: 16306625]

34. Barouch DH, Liu J, Lynch DM, O’Brien KL, La Porte A, Simmons NL, Riggs AM, Clark S, Abbink P, Montefiori DC, Landucci G, Forthal DN, Self SG, Carville A, Mansfield K, Goudsmit J. Protective efficacy of a single immunization of a chimeric adenovirus vector-based vaccine against simian immunodeficiency virus challenge in rhesus monkeys. J Virol 2009;83:9584-90. [PubMed: 19553307]

35. Lemckert AA, Sumida SM, Holterman L, Vogels R, Truitt DM, Lynch DM, Nanda A, Ewald BA, Gorgone DA, Lifton MA, Goudsmit J, Havenga MJ, Barouch DH. Immunogenicity of heterologous prime-boost regimens involving recombinant adenovirus serotype 11 (Ad11) and Ad35 vaccine vectors in the presence of anti-ad5 immunity. J Virol 2005;79:9694-701. [PubMed: 16014931]

36. Thorner AR, Lemckert AA, Goudsmit J, Lynch DM, Ewald BA, Denholtz M, Havenga MJ, Barouch $\mathrm{DH}$. Immunogenicity of heterologous recombinant adenovirus prime-boost vaccine regimens is enhanced by circumventing vector cross-reactivity. J Virol 2006;80:12009-16. [PubMed: 17035318]

37. Santra S, Sun Y, Korioth-Schmitz B, Fitzgerald J, Charbonneau C, Santos G, Seaman MS, Ratcliffe SJ, Montefiori DC, Nabel GJ, Ertl HC, Letvin NL. Heterologous prime/boost immunizations of rhesus monkeys using chimpanzee adenovirus vectors. Vaccine 2009;27:5837-45. [PubMed: 19660588] 
38. Casimiro DR, Bett AJ, Fu TM, Davies ME, Tang A, Wilson KA, Chen M, Long R, McKelvey T, Chastain M, Gurunathan S, Tartaglia J, Emini EA, Shiver J. Heterologous human immunodeficiency virus type 1 priming-boosting immunization strategies involving replication-defective adenovirus and poxvirus vaccine vectors. Journal of virology 2004;78:11434-8. [PubMed: 15452269]

39. Fischer W, Perkins S, Theiler J, Bhattacharya T, Yusim K, Funkhouser R, Kuiken C, Haynes B, Letvin NL, Walker BD, Hahn BH, Korber BT. Polyvalent vaccines for optimal coverage of potential T-cell epitopes in global HIV-1 variants. Nat Med 2007;13:100-6. [PubMed: 17187074]

40. Kong WP, Wu L, Wallstrom TC, Fischer W, Yang ZY, Ko SY, Letvin NL, Haynes BF, Hahn BH, Korber B, Nabel GJ. Expanded breadth of the T-cell response to mosaic human immunodeficiency virus type 1 envelope DNA vaccination. Journal of virology 2009;83:2201-15. [PubMed: 19109395]

41*. Barouch DH, O'Brien KL, Simmons NL, King SL, Abbink P, Maxfield LF, Sun YH, La Porte A, Riggs AM, Lynch DM, Clark SL, Backus K, Perry JR, Seaman MS, Carville A, Mansfield KG, Szinger JJ, Fischer W, Muldoon M, Korber B. Mosaic HIV-1 vaccines expand the breadth and depth of cellular immune responses in rhesus monkeys. Nat Med 2010;16:319-23. This study demonstrates that HIV-1 mosaic antigens expressed by rAd vectors expand CD4+ and CD8+ T lymphocyte breadth and depth in rhesus monkeys. [PubMed: 20173752]

42*. Santra S, Liao HX, Zhang R, Muldoon M, Watson S, Fischer W, Theiler J, Szinger J, Balachandran H, Buzby A, Quinn D, Parks RJ, Tsao CY, Carville A, Mansfield KG, Pavlakis GN, Felber BK, Haynes BF, Korber BT, Letvin NL. Mosaic vaccines elicit CD8+ T lymphocyte responses that confer enhanced immune coverage of diverse HIV strains in monkeys. Nat Med 2010;16:324-8. This study demonstrates that HIV-1 mosaic antigens expressed by DNA/vaccinia vectors expand CD8+ T lymphocyte breadth and depth in rhesus monkeys. [PubMed: 20173754] 